Resenha

\title{
Uma Epistemologia das Políticas Públicas: elementos para a ação pública
}

\author{
An Epistemology of Public Policy: \\ elements for public action
}

Una Epistemologia de las Políticas Públicas: elementos para la acción pública

\section{Une Épistémologie de la Politique Publique: éléments pour l'action publique}

Obra: Políticas Públicas Formulación, implementación y evaluación

Autor: André-Noël Roth Deubel

Idioma: Espanhol

Cidade: Bogotá

Editora: Aurora

Ano: 2002 - 14ª edição: 2019

Páginas: 296

ISBN-13: 978-958-9136-15-7

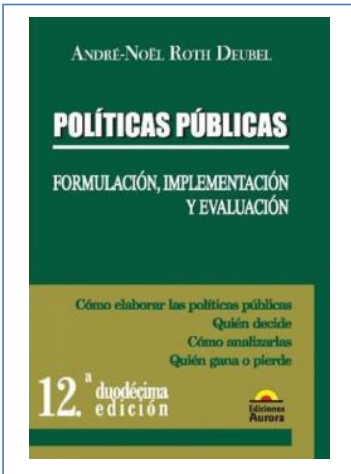

Iván Omar Godoy-Flores ${ }^{1}$

\footnotetext{
${ }^{1}$ Bacharel em Administração de Empresas, Mestre em Ciências Sociais Aplicadas, pesquisador do Grupo de Psicologia Política da Universidad de Tarapacá, Arica, Chile, e pesquisador do Grupo de Estudos e Pesquisas em Psicologia Política, Políticas Públicas e Multiculturalismo da Universidade de São Paulo, Brasil. 


\section{Apresentação}

Que sentido há em resenhar uma obra de políticas públicas publicada pela primeira vez em 2002 e revisada em 2014 (10 a ed.)? Pois há pelo menos três possíveis respostas. a) A obra em questão está na sua nada desprezível $14^{\mathrm{a}}$ edição, b) A obra ainda não foi traduzida para o português e c) A obra considerada um clássico da literatura de políticas públicas está vigente, e constantemente atualizada.

O seu autor, o suíço André-Noël Roth Deubel, residente na capital da Colômbia é académico titular da Faculdade de Direito, Ciências Sociais e Políticas da Universidade Nacional da Colômbia, é referencia em livros e artigos publicados em toda Ibero América. É também membro de diversos conselhos editoriais de revistas especializadas em políticas públicas na América Latina.

\section{Políticas Públicas}

O livro Políticas Públicas Formulación, implementación y evaluación tem por epígrafe: Cómo elaborar Cómo analizarlas Quién gana Quién pierde. O que já nos da uma ideia que a obra começa citando autores como Lasswell, Dye, Sabatier, Fischer, Lindblom e tantos outros. Porém Roth vai além; são amplas as referencias de autores principalmente ocidentais que abarcam uma infinidade de temas do Estado em ação. Um esforço para apresentar as políticas públicas de $\mathrm{A}$ a $\mathrm{Z}$.

Um dos primeiros pontos que destacam na obra são os elementos epistémicos que dão um adequado fundamento filosófico aos marcos teóricos apresentados em cada capítulo, fartamente referenciados.

O capítulo 1, Estado, política pública y análisis de políticas públicas, apresenta um panorama amplo que inicia nos primórdios das políticas públicas, além de definições fundamentais e sua perspectiva como atividade académica e profissional, assunto compartido por diversos autores ibero americanos como o mexicano Julio Franco (2017), os colombianos Balanzó e Herrera Kit (2016) e os brasileiros Marques e Faria (2018).

A perspectiva conceitual de Roth (2019) é bastante ampla nesta obra. Ela vai do modernismo ao posmodernismo, do positivismo ao pospositivimo, passando pela teoria crítica. Mas também é uma obra de referencia para muitos governos quando de elaboração e critérios de formulação se trata (Subdere, 2009).

O capítulo 2 - Los enfoques teóricos para el análisis de las políticas públicas, recolhe as diversas perspectivas epistemológicas para dar sustento a cada proposta provinda de distintos autores. Roth (2019) apoia-se na teoria do conhecimento para apresentar os paradigmas vinculados às mais importantes teorias e marcos teóricos das políticas públicas. Este capítulo está especialmente recomendado para quem quiser conhecer de forma integral as correntes filosóficas detrás dos fundamentos das políticas públicas. Estes temas foram ampliados no capítulo 1 - Las políticas públicas y sus principales enfoques analíticos do livro Enfoques para el análisis de políticas públicas (Roth, 2010).

O capítulo 3 - Identificación de problemas públicos y agenda política é um esforço para lograr uma definição dos processos de construção de problemas públicos a partir das problemáticas 
socioeconómicas. Neste sentido Roth (2019) antecipa-se dizendo que:

[...] a definição dos problemas públicos é o resultado das lutas libradas pelo conjunto de atores ou "públicos" interessados, para impor uma representação, uma etiqueta, com a maior vantagem possível para seus interesses (em um sentido amplo) (p. 120) (tradução nossa).

Neste capítulo são abundantes as referencias de autores que já integram a historia das correntes de pensamento sobre políticas públicas e que influenciaram a filosofia de sua análise.

O capitulo 4 - Formulación de soluciones y decisión, centra-se nas técnicas e modelos de tomada de decisão sempre apoiada por exemplos da historia política ocidental. Porém Roth (2019) sublinha a importância da participação da sociedade civil na formulação e na tomada de decisão e conclui dizendo:

A participação tornou-se imperativa em vários âmbitos da vida política latino americana. $\mathrm{O}$ enfoque participativo na formulação da política pública tornou-se um modus operandi, não só politicamente legítimo, senão também validado jurídica e administrativamente ( $\mathrm{p}$. 182) (tradução nossa).

De fato são diversas as instancias internacionais que promovem a participação social não só nas políticas públicas como também na gestão pública (Godoy-Flores, Palleres, \& Archila, 2019), na qual cada vez mais assemelham-se não só no conceito mas também na práxis.

O capítulo 5 - Implementación de las decisiones apresenta uma serie de enfoques e condições necessárias para a implantação de soluções mediante processos de decisões em temas como a burocracia, aprendizagem, informação e negociação. Este capítulo está apoiado por uma serie de tabelas que facilitam a compreensão dos enfoques de implantação das políticas públicas. O autor faz permanentes referencias á realidade latino americana como uma forma de aterrissar os conceitos muitos deles europeus e estadunidenses.

Finalmente, o capítulo 6 - La evaluación de las políticas públicas, é um conteúdo esperado na apresentação de um extenso processo de política pública. E é talvez o capítulo mais crítico do autor. Talvez pelo fato de que Roth tenha como uma de suas especialidades a análise e a avaliação de políticas públicas. Para Roth é importante que os governos e os cidadãos saibam o que foi obtido por meio das ações (públicas) empreendidas.

Porém o desenvolvimento da avaliação de políticas públicas não encontra sua legitimação unicamente nas deficiências do Estado, senão também no fato em que os problemas que este busca resolver, controlar ou mitigar por meio de suas próprias ações públicas são sempre mais complexos e duvidosos em quanto aos meios, resultado e efeitos (p. 227) (tradução nossa).

$\mathrm{Na}$ conclusão do texto, chama a atenção o esforço prospectivo das políticas públicas em quanto á participação social e a possibilidade de empoderamento dos grupos de interesse. Propõe ainda, reflexões sobre o papel do Estado e da sociedade civil enquanto á tomada de decisões nos assuntos públicos. Roth defende uma maior participação democrática por parte dos atores sociais e políticos. Segundo Roth, estas pressões obrigam ao Estado a desenvolver novos mecanismos e lugares de participação política 
que significam na prática menos governo e mais governança.

Sem mencionar o papel da doutrina neoliberal nas decisões políticas, Roth propõe que o Estado está atravessado pela sociedade civil organizada: de um lado pelo capital financeiro internacionalizado $e$, do outro pelos mecanismos sociais. Nessa relação gera-se uma crise de desconfiança generalizada e o desprestigio da classe política que finalmente, junto com o poder legislativo geram políticas que não satisfazem a sociedade civil. Ou pior, geram políticas para garantir os assuntos (business) dos grandes grupos económicos. Majone (2014 [1997]) traduz bem esta situação:

Se as políticas de governo não tem o propósito de fechar as brechas da desigualdade, é difícil outorga-lhes a qualificação de públicas (p. 31, tradução nossa).

Roth, no entanto, é enfático em apontar para o fato de que um governo para ser definido como responsável não pode tomar decisões sem ter um mínimo de interesse pelas consequências que estas implicam além do curto prazo.

\section{Ação Pública}

Destaca na obra Políticas Públicas, uma questão que atravessa todo o pensamento sobre esta disciplina: a ação pública. Embora em certas partes da obra, a ação pública seja tratada de forma indistinta das políticas públicas, Roth faz questão de conceber que a ação pública reflete a tensão existente entre duas formas de legitimidade. De um lado a legitimidade tradicional baseada no respeito á lei e aos regulamentos e, de outro, uma legitimidade fundamentada nos objetivos e nos resultados da ação. O enfoque tradicional da legitimidade da política pública, fundamentada no respeito às regras $\mathrm{e}$ procedimentos jurídicos, tende a ser substituído por uma legitimidade da ação pública baseada no logro dos resultados com maior participação social (Roth, 2019 [2002]).

Através da análise destes processos políticos y sociais que legitimam e concretam a orientação das políticas ou ações públicas, é possível dar conta empiricamente do tipo de Estado, de sua natureza, evolução e transformação, mas também de suas relações com a sociedade e viceversa. (2019 [2002]: 62, tradução nossa).

Para Silva (2012, 2013, 2018ab), a proposta da ação pública produz um giro ontológico na compreensão do que são políticas públicas na atualidade e no entendimento de qual é seu devido lugar na dinâmica social e política das relações humanas.

Roth, citando a Lascoumes e Le Galès (2007) argumenta que a existência de uma perspectiva francesa de política pública deve-se á consideração das perspectivas anglo saxões eram insuficientemente críticas frente aos poderes do Estado e, por outra parte, por estimar que a Policy Science focava-se desde uma perspectiva demasiado gerencial (topdown) e de problem solving pouco sociológico. Por isso, se tende também a rechaçar o nome de análise das políticas públicas y preferirem a denominação sociologia ou sociologia política da ação pública.

Para Silva (2018a), o lugar das políticas públicas na ação pública está estreitamente associado ao de governança 
democrática, pois "são instrumentos de promoção de mudança social. Esse esquema de pensamento rompe com a perspectiva estadocêntrica convencional e unipolar [...]" (p. 196).

Roth (2019 [2002]) distingue tres tradições francesas de estudos do Estado e suas ações. Então, a ação pública seria parte da terceira tradição. A primeira é a da ciência administrativa, onde nas políticas do Estado deveriam estar integrados atores externos ás instituições particularmente nas fases de agenda e implantação; a segunda tradição seria o marxismo. Como caraterística distintiva da cultura cívica francesa, permanece a ideia de que a ação pública se encontra irremediavelmente sob as relações de dominação (Leca \& Muller, 2008: 46-47). E a terceira e ultima tradição seria a sociologia das organizações com os trabalhos de Crozier e Friedberg (1977) que mostraram que a ação pública não pode se deduzir das estruturas sociais ou económicas (visão tecnocrática), pois esta passa pela análise detalhado dos processos de interação entre os atores que atuam, não de forma racional, senão de maneira estratégica (Roth, 2019 [2002]).

Para Fontaine (2015), a sociología da ação pública interessa a muitos analistas de políticas públicas preocupados por ampliar o espectro de análise e incluir interações, atores, ideais que não são específicamente do Estado.

No livro Análisis de políticas públicas: Perspectivas pragmáticas, interpretativas, de redes y de innovación pública organizado por Roth (2017) são apresentados dois capítulos sobre a ação pública sob perpectivas empíricas que valem a pena considerar. $\mathrm{O}$ primeiro deles, assinado por Philippe Zittoun entitula, Hacia um enfoque pragmático de la acción pública; e o segundo, dos autoras Natalia Suárez e Stephany Vargas, entitula-se La acción pública: una mirada desde la experiencia de los problemas públicos.

Outra obra, Manual de Consultoria en asuntos públicos de Sara Tadlaoui (2013) cita a Roth entre diversos autores para:

$$
\begin{aligned}
& \text { destacar os importantes esforços } \\
& \text { investigativos, elaborados desde } \\
& \text { diversas escolas teóricas, para } \\
& \text { explicar as dinâmicas e } \\
& \text { transformações da ação pública que } \\
& \text { cada vez menos pode ser entendida } \\
& \text { sob a lógica top-down, onde o } \\
& \text { Estado não só é entendido como } \\
& \text { ator central, senão quase único [...] } \\
& \text { (p. 20) (tradução nossa). }
\end{aligned}
$$

Certa vez, perguntei a André-Noël Roth sobre o que há de ação pública na América Latina. Ele me respondeu que, neste continente, o conceito está ainda submerso nas políticas públicas sem que se faça distinção alguma. $\mathrm{O}$ que representa todo um desafio para elaboradores, analistas e avaliadores de políticas públicas mais democráticas.

\section{Considerações Finais}

Esta obra de não pretende ser um manual didático de políticas públicas nem busca criar novos marcos teóricos.

É uma leitura amena, sem complexidades adicionadas. O livro pode ser lido a partir de qualquer capítulo que seja do interesse do leitor.

$\mathrm{Na}$ Apresentação da obra Políticas Públicas Elaboración, implementación y evaluación, André-Noël Roth propõe entregar pistas ou respostas para seus leitores e 
também motivar para intentar entender melhor a ação pública; para que esta resulte mais comprometida com a dignidade de todas as pessoas, aprofundar a democracia e melhorar a vida cotidiana de toda cidadania. Na pratica são valores idôneos para uma ação pública permanentemente ameaçada pela doutrina neoliberal y pelos governos autoritários.

Roth tem uma preocupação pelo desenvolvimento recente das políticas públicas no que se refere à governança, pois percebe que como ação pública as políticas deixam de ter um único ator dominante (Governo/Estado) e passam a conceber a solução dos problemas públicos como o resultado de um processo que involucra a uma pluralidade de atores - e também os movimentos sociais como demandas de melhor qualidade de vida. Desta forma o autor argumenta as bases epistemológicas para o enfoque de uma ação pública que vai justamente dos movimentos sociais às políticas púbicas.

A obra Políticas Públicas é uma referencia obrigatória nos assuntos mais amplos das políticas públicas, ou melhor, da ação pública.

\section{Referências Bibliográficas}

Balanzó, Alejandro., \& Herrera Kit, Patricia. (2016). Cuando la descentralización no es suficiente: conceptos para la territorialización de políticas. Em Marco Moreno., \& Luís Martínez. (Edits.), Desafíos para el desarrollo Políticas públicas y sostenibilidad (pp. 13-44). Santiago: Ril - Universidad Central.

Crozier, Michel, \& Friedberg, Erhard (1977). L'acteur et le système. Paris: Seuil.

Fountaine, Guillaume. (2015). El análisis de políticas públicas Conceptos, teorías y métodos. Barcelona: Anthropos.

Franco, Julio (2017). Diseño de Políticas Públicas. México: IEXE.

Godoy-Flores, Iván., Palleres, Oscar., \& Archila, Jesús. (2019). Carta de Lisboa y Ley 20.500: análisis comparativo. Em Christian Benítez Núñez., Jesús Enrique Archila Guío., \& Filiberto Eduardo Manrique Molina. Ius commune en perspectiva sistémica latinoamericana. (pp. 154-175). Bogotá: Ibañez.

Lascoumes, Pierre, \& Le Galès, Patrick (2007). Sociologie de l'action publique. Paris: Armand Colin.

Leca, Jean., \& Muller, Pierre (2008). Y a-t-il une approche française des politiques publiques? Em Olivier Giraud., \& Philippe Warin. (Eds.), Politiques publiques et démocratie (pp. 46-47). Paris: La Découverte.

Majone, Giandomenico (2014). Evidencia, argumentación y persuasión en la formulación de políticas. México: FCE. (Originalmente publicado em 1997).

Marques, Eduardo., \& Faria, Carlos. (Eds.). (2018). A polítca pública como campo multidisciplinar. São Paulo: Unesp. 
Roth, André-Noël. (2010). Las políticas públicas y sus principales enfoques analíticos. Em André-Noël Roth. (Ed.), Enfoques para el análisis de políticas públicas (pp. 17-65). Bogotá: Universidad Nacional de Colombia. https://www.uneditorial.com/enfoquespara-el-analisis-de-politicas-publicaspolitica-colombiana.html

Roth, André-Noël. (2017). Análisis de políticas públicas Perspectivas pragmáticas, interpretativas, de redes y de innovación pública. Bogotá: Universidad Nacional de Colombia.

Roth, André-Noël. (2019). Políticas públicas Formulación, implementación $\quad y$ evaluación. Bogotá: Aurora. (Originalmente publicado em 2002).

Silva, Alessandro (2012). Psicologia Política, movimentos sociais e políticas Públicas. Tese de Livre Docencia. Universidade de São Paulo. São Paulo.

Silva, Alessandro Soares da. (2013). Um enfoque psicopolítico das políticas públicas. Revista Electrónica de Psicología Política, 11(30), 1-6. Acessado em 12 de maio de 2019, de: https://www.researchgate.net/publication/3446
64075_Um_Enfoque_Psicopolitico_das_Politi cas Publicas Un Enfoque Psicopolitico de 1 as Politicas Publicas

Silva, Alessandro (2018). A Ação Pública: um outro olhar sobre Estado, Sociedade e Políticas Públicas. Revista Gestão \& Políticas Públicas, 8(1), 194-204. Acessado em 17 de abril de 2019, de: https://www.revistas.usp.br/rgpp/arti cle/view/175154

Silva, Alessandro (2018b). Um Esboço do que poderia ser a Psicologia Política da Ação Pública. Cadernos da ANPEPP, GT 62, Psicologia Política. Acessado em 25 de fevereiro de 2018, de: https://www.researchgate.net/publicat ion/344134091 Um Esboco do que po deria ser a Psicologia Politica da Acao Publica

Subdere. (2009). Guía metodológica para la formulación de políticas públicas regionales. Santiago: División de Políticas y Estudios, Subsecretaría de Desarrollo Regional y Administrativo.

Tadlaoui, Sarah. (2013). Manual de consultoría en asuntos públicos. Bogotá: Universidad Externado de Colombia.

Recebido em 14/07/2019. Aceito em 23/09/2019. 